\title{
The long way to defeating Chagas cardiomyopathy
}

\author{
Mario Petretta, $M D,{ }^{a}$ and Alberto Cuocolo, $M^{b}$ \\ a Department of Translational Medical Sciences, University Federico II, Naples, Italy \\ b Department of Advanced Biomedical Sciences, University Federico II, Naples, Italy
}

Received Jan 8, 2018; accepted Jan 8, 2018

doi: $10.1007 / \mathrm{s} 12350-018-1238-3$

\section{See related article, pp. 1569-1579}

Chagas disease was named after the Brazilian hygienist, scientist, and bacteriologist Carlos Chagas, who in 1909 identified Trypanosoma cruzi as the pathogen agent in a 2-year-old girl named Berenice who was feverish with enlarged spleen and liver and swollen lymph nodes. Chagas also discovered that triatoma bugs are vectors of the parasite and that various animals (first, the armadillo) are wild reservoirs for the parasite. Chagas named the parasite in honor of his mentor, the Brazilian physician and bacteriologist Oswaldo Gonçalves Cruz (1872 to 1917), founder of the Oswaldo Cruz Institute. ${ }^{1}$ The disease is, of course, much older than Chagas' discovery and has been associated with humans shortly after they arrived in the Americas some 15,000 years ago. T. cruzi has been found in mummies from northern Chile and southern Peru that are nearly 9000 years old. Chagas disease is becoming a worldwide health and economic burden due to multiple bioecological, sociocultural, and political factors, including migration. The World Health Organization estimates that 8 to 10 million people are infected worldwide, mostly in Latin America where the disease remains endemic. ${ }^{2}$ A recent study estimates global costs of $\$ 7.19$ billion/year for Chagas disease and, noteworthy, more than $10 \%$ of these costs emanate from the United States and Canada, where Chagas disease is not recognized as a significant health problem. ${ }^{3}$

Reprint requests: Alberto Cuocolo, MD, Department of Advanced Biomedical Sciences, University Federico II, Naples, Italy; cuocolo@unina.it

J Nucl Cardiol 2019;26:1580-3.

$1071-3581 / \$ 34.00$

Copyright (c) 2018 American Society of Nuclear Cardiology.
Chagas disease is characterized by an acute and a chronic phase of infection. In the acute phase most patients are asymptomatic, while the remaining infected individuals usually show a non-specific febrile disease. Severe acute disease is rare, occurring in $<1 \%$ of patients, and the clinical manifestations include acute myocarditis, pericardial effusion, and/or meningoencephalitis. ${ }^{4}$ In the chronic phase two well-defined forms of disease are distinguished: indeterminate (latent preclinical) and determinate (clinical), the latter subdivided into cardiac, digestive, and cardiodigestive forms. Although megaesophagus and megacolon produce typical clinical conditions in about $10 \%$ of patients, cardiac involvement is the most serious and frequent manifestation (about 30\% of patients) of chronic Chagas disease. $^{5}$

As Chagas disease is perceived as restricted to Mexico and Latin America, in the United States and Europe the condition is usually ignored in the differential diagnosis of cardiomyopathies. Thus, Chagas disease may be misdiagnosed as idiopathic cardiomyopathy. As a consequence, patients with Chagas disease are not informed about their infection and can potentially transmit the parasite through blood or organ donation.

The clinical presentation of cardiac Chagas disease varies widely according to the extent of myocardial damage. It manifests as three major syndromes that may coexist in the same patient: arrhythmic, heart failure, and thromboembolism (systemic and pulmonary). Several pathogenetic mechanisms have been called into question to explain the development of Chagas heart disease: cardiac dysautonomia, microvascular disturbances, parasite-dependent myocardial damage, and immune-mediated myocardial injury. There is ample experimental and clinical evidence that functional and structural microvascular abnormalities occur in patients with Chagas cardiomyopathy, possibly due to the 
inflammatory process and/or autonomic disturbances caused by $T$. cruzi infection. ${ }^{6}$

Symptoms suggestive of myocardial ischemia such as atypical angina pectoris are frequent in patients with Chagas heart disease. Most of these patients have concomitant transient or definite ST-T changes on a 12-lead electrocardiogram and abnormal $\mathrm{Q}$ waves compatible with electrically inactive left ventricular (LV) areas. ${ }^{7}$ Similar to coronary heart disease, segmental LV wall motion abnormalities are common in patients with chronic Chagas disease and are even occasionally detected when the LV chamber is already globally dilated. Despite the occurrence of these manifestations, suggesting the presence of myocardial ischemia, invasive coronary angiography in Chagas' cardiomyopathy nearly invariably demonstrates the absence of significant obstructive coronary disease at the epicardial level. ${ }^{8}$ On the other hand, several studies demonstrated myocardial perfusion abnormalities in patients with Chagas disease and angiographically normal coronary arteries, supporting the concept of abnormal myocardial flow regulation at the microvascular level. ${ }^{6}$ Accordingly, impairment of endothelium-dependent (acetylcholine) and endothelium-independent (hyperventilation, nitrates, and adenosine) coronary vasodilatation has been described, also if with mixed results, in patients with Chagas heart disease. ${ }^{9}$

Kuschnir et al. ${ }^{10,11}$ first reported a reduction in global myocardial flow measured with ${ }^{86} \mathrm{Rb}$ at rest and in response to physical exercise in patients with Chagas disease compared to control subjects. After these pioneristic reports, myocardial perfusion abnormalities have been described in patients with Chagas disease and angiographically normal coronary arteries using ${ }^{201} \mathrm{Tl}$ stress-redistribution planar scintigraphy ${ }^{12}$ and singlephoton emission computed tomography (SPECT), ${ }^{13}$ or ${ }^{99 \mathrm{~m}} \mathrm{Tc}$-sestamibi SPECT. ${ }^{14}$ Interestingly, the progression of LV systolic dysfunction may be associated with reversible perfusion defects at first examination and an increase in perfusion defects at rest at the second examination performed after $\sim 5.6$ years of followup. ${ }^{15}$ Wall motion abnormalities may be induced during stress echocardiography in Chagas disease patients despite angiographically normal coronary arteries, even in those without overt heart disease and with normal LV wall motion at baseline, ${ }^{16}$ further supporting the role of abnormalities in coronary circulation in these patients. However, the ultrastructural alterations in myocardium observed even in Chagasic asymptomatic subjects ${ }^{17}$ and myocardial sympathetic denervation might contribute to contractile dysfunction and blunted chronotropic response during dobutamine infusion. ${ }^{13}$

Several animal models, including mice, rats, rabbits, hamster, guinea pig, chicken, dogs, and monkeys, have been employed for Chagas disease. All of these models have some drawback, and the most appropriate animal model for translation into humans is still unclear. The requisites of a good experimental model to study Chagas disease have been established. ${ }^{18}$ In this issue of the Journal, Tanaka et al. ${ }^{19}$ investigated whether myocardial perfusion disturbance precedes LV systolic dysfunction and tested the hypothesis that prolonged use of dipyridamole could reduce myocardial perfusion defect in an experimental model of chronic Chagas cardiomyopathy in hamsters. For the purpose of the study, Tanaka et al. ${ }^{19}$ properly used the Syrian hamster Mesocricetus auratus that when infected with the Ystrain develops a cardiomyopathy resembling human Chagas' disease. The results show that myocardial perfusion disturbance is frequent in experimental chronic Chagas cardiomyopathy and precedes the development of myocardium systolic dysfunction. Noteworthy, the prolonged administration of dipyridamole was associated with a significant reversion of resting myocardial perfusion defects confirming the occurrence of reversible microvascular dysfunction in experimental chronic Chagas cardiomyopathy. Surprisingly, dipyridamole slight increased interstitial fibrosis in controls so that no difference was detectable in the comparison with the infected groups (see Fig. 3 of Tanaka et al.). Furthermore, from Table 1 of Tanaka et al. ${ }^{19}$ it appears that the reduction in LV ejection fraction after dipyridamole is comparable to placebo treatment. This finding seems in agreement with the paradigm shift in favor of antiparasitic treatment for all adult chronic Chagas patients. ${ }^{20}$

Nevertheless, the findings of Tanaka et al. ${ }^{19}$ give support for future prospective studies testing the impact of drugs targeting the myocardial perfusion derangement over the myocardial systolic dysfunction progression in chronic Chagas cardiomyopathy.

Recently, it has been demonstrated for the first time that dipyridamole has a trypanocidal effect in vitro on $T$. cruzi proliferation and decreases parasitaemia in infected mice. $^{21}$ Interestingly, in vivo the trypanocidal drug nifurtimox at a dosage of $40 \mathrm{mg} / \mathrm{kg}$ with or without dipyridamole had a therapeutic effect, with $84 \%$ to $92 \%$ survival rate and elimination of parasitaemia and heart tissue amastigotes, the common intracellular lifecycle stage of T. cruzi. Nifurtimox $10 \mathrm{mg} / \mathrm{kg}$, the recommended dose for treating Chagas disease in humans, had only subtherapeutic effect with no survival and persistence of amastigotes, inflammation, and fibrosis in heart tissue; adding dipyridamole the survival rate increased to $85 \%$, and all tested parameters were significantly improved. ${ }^{21}$ Of note, dipyridamole alone, despite the trypanocidal effect in vitro, did not change the amastigote density in cardiac tissue, thus other mechanisms are probably involved in the beneficial effects of the drug. 
Theoretically, the beneficial effect of dipyridamole could be associated with mechanisms at least in part independent from its effect on coronary vasodilatation and inhibitions of platelet aggregation. Kuschnir et al. ${ }^{22}$ reported that dipyridamole improves cardiac contractility of hypokinetic areas and ejection fraction in patients with Chagas cardiomyopathy. Dipyridamole may also act as an immunomodulator agent, an effect mainly mediated by adenosine $A_{2 A}$ receptors, reducing interleukin- 6 and tumor-necrosis factor- $\alpha$, while increasing interleukin-10 levels, so counteracting necrosis, fibrosis, and cardiac remodeling associated with severe inflammation. $^{23}$ Finally, the production of free radicals increases during Chagasic cardiomyopathy development, due to mitochondrial damage and inefficient antioxidant defense, and dipyridamole may act as a free radical scavenger, whose capacity is even greater than $\alpha$ tocopherol and vitamin C. ${ }^{24}$ However, in the study of Tanaka et al. ${ }^{19}$ quantitative histopathology findings showed comparable degrees of myocardial inflammation and fibrosis in both infected groups treated with placebo or dipyridamole, indicating that the effect of prolonged dipyridamole in reducing myocardial perfusion defects was not due to a reduction of myocardial inflammation, eventually associated to the drug effect.

An important aspect that deserves to be investigated is whether cardiac sympathetic denervation, assessed by single-photon emission computed tomography or positron emission tomography, ameliorates after dipyridamole treatment. Cardiac sympathetic denervation has been clearly demonstrated in chronic Chagas cardiomyopathy and a correlation between sympathetic denervation and the occurrence of severe ventricular arrhythmia has been reported in patients with normal or mildly reduced LV ejection fraction. ${ }^{25}$ The severity of ventricular arrhythmias correlates with the extent of myocardial sympathetic denervation, but not with myocardial fibrosis extent in chronic Chagas cardiomyopathy. ${ }^{26}$ Despite the shortage of systematic studies in Chagas disease investigating the prevalence of sudden death, its mechanisms, risk factors, and prevention it is generally admitted that sudden death is the major cause of death in this disease. ${ }^{27}$ From the studies carried out in Chagas' patients receiving implantable cardioverter defibrillator therapy, it has become clear that sustained ventricular tachycardia is the most frequently observed life-threatening ventricular arrhythmia, that about $30 \%$ of patients develop ventricular fibrillation without having sustained ventricular tachycardia as a precursor of the index event, and that sustained ventricular tachycardia or ventricular fibrillation may affect about $10 \%$ of Chagas' disease patients with no LV systolic dysfunction. ${ }^{28}$ It should be also considered that the destruction of the parasympathetic innervation could induce an increased sympathetic tone with either a direct effect in arrhythmogenesis via altering the electrophysiologic properties of the heart or an indirect effect via other mechanisms, such as increased oxygen demand by catecholamine, increased coronary vasomotor tone, and augmented platelet adhesiveness. ${ }^{29}$ However, currently, there are no realistic techniques for imaging the cardiac parasympathetic nervous system.

It should be also considered that Tanaka et al. ${ }^{19}$ used an adaptation of a pinhole collimator to a gamma camera designed for clinical use. This may have caused an underestimation of the myocardial perfusion disturbance that could be more accurately evaluated by other quantitative dedicated imaging techniques, and advances in animal preparation, anesthesia, radiotracers, and images post-processing. ${ }^{30}$ Future researches, mainly focused on positron emission tomography and magnetic resonance imaging techniques, have the potential to contribute to a better understanding of chronic Chagas cardiomyopathy and eventually of the role, if any, of dipyridamole in helping to prevent or treat this condition.

\section{Disclosure}

$M$ Petretta and A. Cuocolo declare that they have no conflict of interest.

\section{References}

1. Chagas C. Neue trypanosomen: Vorläufige mitteilung. Arch Schiffs Trop Hyg. 1909;13:120-2.

2. World Health Organization. Chagas disease: Control and elimination. World Health Organization. World Health Assembly report. Geneva: World Health Organization; 2010. pp. 1-4.

3. Lee BY, Bacon KM, Bottazzi ME, Hotez PJ. Global economic burden of Chagas disease: A computational simulation model. Lancet Infect Dis. 2013;13:342-8.

4. Prata A. Clinical and epidemiological aspects of Chagas disease. Lancet Infect Dis. 2001;1:92-100.

5. Nunes MC, Dones W, Morillo CA, Encina JJ, Ribeiro AL, Council on Chagas Disease of the Interamerican Society of Cardiology. Chagas disease: An overview of clinical and epidemiological aspects. J Am Coll Cardiol. 2013;62:767-76.

6. Marin-Neto JA, Cunha-Neto E, Maciel BC, Simões MV. Pathogenesis of chronic Chagas heart disease. Circulation. 2007;115:1109-23.

7. Simões MV, Ayres EM, Santos JL, Schmidt A, Pintya AO, Maciel $\mathrm{BC}$, et al. Detection of myocardial ischemia in chronic Chagas disease patients with atypic precordial pain by exercise and Holter tests. Arq Bras Cardiol. 1993;60:315-9.

8. Hagar JM, Rahimtoola SH. Chagas' heart disease in the United States. N Engl J Med. 1991;325:763-8.

9. Rossi MA, Tanowitz HB, Malvestio LM, Celes MR, Campos EC, Blefari V, et al. Coronary microvascular disease in chronic Chagas cardiomyopathy including an overview on history, pathology, and 
other proposed pathogenic mechanisms. PLoS Negl Trop Dis. 2010;4:e674.

10. Kuschnir E, Kustich F, Epelman M, Santamarina N, Podio RB. Valoration de fluxo miocardico con Rb-86, en pacientes con cardiopatia chagasica, con insuficiencia coronaria y en controles normales. Parte 1: Estudios basales. Arq Bras Cardiol. 1974;27:187-96.

11. Kuschnir E, Kustich F, Epelman M, Santamarina N, Podio RB. Valoration de fluxo miocardico con Rb-86, en pacientes con cardiopatia chagasica, con insuficiencia coronaria y en controles normales. Parte 2: Respuesta al ejercicio y a la cardiotonificación aguda. Arq Bras Cardiol. 1974;27:721-32.

12. Marin-Neto JA, Marzullo P, Marcassa C, Gallo Junior L, Maciel $\mathrm{BC}$, Bellina CR, et al. Myocardial perfusion abnormalities in chronic Chagas' disease as detected by thallium-201 scintigraphy. Am J Cardiol. 1992;69:780-4.

13. Simões MV, Pintya AO, Bromberg-Marin G, Sarabanda AV, Antloga CM, Pazin-Filho A, et al. Relation of regional sympathetic denervation and myocardial perfusion disturbance to wall motion impairment in Chagas' cardiomyopathy. Am J Cardiol. 2000;86:975-81.

14. Peix A, García R, Sánchez J, Cabrera LO, Padrón K, Vedia O, et al. Myocardial perfusion imaging and cardiac involvement in the indeterminate phase of Chagas disease. Arq Bras Cardiol. 2013;100:114-7.

15. Hiss FC, Lascala TF, Maciel BC, Marin-Neto JA, Simoes MV. Changes in myocardial perfusion correlate with deterioration of left ventricular systolic function in chronic Chagas' cardiomyopathy. J Am Coll Cardiol Imaging. 2009;2:164-72.

16. Acquatella H, Perez JE, Condado JA, Sanchez I. Limited myocardial contractile reserve and chronotropic incompetence in patients with chronic Chagas' disease: Assessment by dobutamine stress echocardiography. J Am Coll Cardiol. 1999;33:522-9.

17. Carrasco Guerra HA, Palacios-Prü E, Dagert de Scorza C, Molina C, Inglessis G, Mendoza RV. Clinical, histochemical, and ultrastructural correlation in septal endomyocardial biopsies from chronic Chagasic patients: Detection of early myocardial damage. Am Heart J. 1987;113:716-24.

18. World Health Organization. Report of the Scientific Working Group on the development and evaluation of animal models for Chagas' disease. Geneva, 1984.

19. Tanaka DM, de Oliveira LFL, Marin-Neto JA, Dias Romano MM, de Carvalho EEV, de Barros Filho ACL, et al. Prolonged dipyridamole administration reduces myocardial perfusion defects in experimental chronic Chagas cardiomyopathy. J Nucl Cardiol. 2018. https://doi.org/10.1007/s12350-018-1198-7.

20. Viotti R, Alarcón de Noya B, Araujo-Jorge T, Grijalva MJ, Guhl F, López MC, et al. Latin American network for Chagas disease, NHEPACHA. Towards a paradigm shift in the treatment of chronic Chagas disease. Antimicrob Agents Chemother. 2014;58:635-9.

21. Santeliz S, Caicedo P, Giraldo E, Alvarez C, Yustiz MD, Rodríguez-Bonfante $\mathrm{C}$, et al. Dipyridamole potentiated the trypanocidal effect of nifurtimox and improved the cardiac function in NMRI mice with acute chagasic myocarditis. Mem Inst Oswaldo Cruz. 2017;112:596-608.

22. Kuschnir E, Sgammini H, Castro R, Evequoz C, Ledesma R. Miocardiopatia chagasica cronica: Efectos del dipiridamol sobre la dinamica ventricular. Arq Bras Cardiol. 1983;41:373-8.

23. Haskó G, Linden J, Cronstein B, Pacher P. Adenosine receptors: Therapeutic aspects for inflammatory and immune diseases. Nat Rev Drug Discov. 2008;7:759-70.

24. Kim HH, Liao JK. Translational therapeutics of dipyridamole. Arterioscler Thromb Vasc Biol. 2008;28:s39-42.

25. Miranda CH, Figueiredo AB, Maciel BC, Marin-Neto JA, Simões MV. Sustained ventricular tachycardia is associated with regional myocardial sympathetic denervation assessed with ${ }^{123} \mathrm{I}-$ metaiodobenzylguanidine in chronic Chagas cardiomyopathy. J Nucl Med. 2011;52:504-10.

26. Gadioli LP, Miranda CH, Pintya AO, de Figueiredo AB, Schmidt A, Maciel BC, et al. The severity of ventricular arrhythmia correlates with the extent of myocardial sympathetic denervation, but not with myocardial fibrosis extent in chronic Chagas cardiomyopathy: Chagas disease, denervation and arrhythmia. J Nucl Cardiol. 2016;25:75-83.

27. Rassi A Jr, Rassi SG, Rassi A. Sudden death in Chagas' disease. Arq Bras Cardiol. 2001;76:75-96.

28. Bestetti RB, Cardinalli-Neto A. Sudden cardiac death in Chagas' heart disease in the contemporary era. Int J Cardiol. 2008;131:917.

29. Oliveira NK, Ferreira RN, Lopes SDN, Chiari E, Camargos ERDS, Martinelli PM. Cardiac autonomic denervation and expression of neurotrophins NGF and BDNF and their receptors during experimental Chagas disease. Growth Factors. 2017;35:161-70.

30. Gargiulo S, Greco A, Gramanzini M, Petretta MP, Ferro A, Larobina $\mathrm{M}$, et al. PET/CT imaging in mouse models of myocardial ischemia. J Biomed Biotechnol. 2012;2012:541872. 